Brit. J. vener. Dis. (1957), 33, 249.

\title{
SATURATED SYNTHETIC LECITHINS IN VDRL AND KOLMER ANTIGENS FOR THE SERO-DIAGNOSIS OF SYPHILIS*
}

\author{
BY \\ DAVID B. TONKS AND ROVELLE H. ALLEN \\ WITH THE TECHNICAL ASSISTANCE OF \\ EVELYN FOWLER AND DEBORAH HAIGHT
}

From the Clinical Laboratories, Laboratory' of Hygiene, Department of National Health and Welfare, Ottawa, Canada

When pure individual synthetic lecithins became available for study (Baer and Kates, 1949, 1950), there was immediate interest in their possible use in cardiolipin antigens as substitutes for Pangborn lecithin. Rosenberg (1949) reported briefly on synthetic $\mathbf{L}-\alpha$-(dipalmitoyl)-lecithin in antigens for the Hinton, Kline, Rein-Bossack, VDRL, and Kolmer tests. He found that replacement of Pangborn's lecithin by identical amounts of synthetic lecithin gave antigens which were reactive. Kline (1950) found that $\mathrm{L}-\alpha$-(dimyristoyl)-lecithin gave reactive antigens, and Allen and Tonks (in a publication by Baer, Martin, Allen, and Tonks, 1951) reported that this compound and its optical isomer, D- $\alpha$-(dimyristoyl)-lecithin, when used in the same concentrations, gave VDRL antigens of similar reactivities. Faure and Maréchal (1952) found that the synthetic lecithins were unstable and concluded that they were not suitable for antigens for the Kline, Debains, and Kolmer tests. However, improved procedures for the preparation and purification of the lecithins (Baer and Maurukas, 1952; Baer, 1953) resulted in more stable, crystalline materials. After extensive studies with crystalline L- $\alpha$-(dimyristoyl)-lecithin, Kline (1954 a, b, 1955) reported favourably on its use in antigens for his flocculation test. Reyn, Bentzon, and Hartmann (1956) studied one batch of crystalline $L-\alpha-$ (dimyristoyl)-lecithin in complement-fixation and VDRL antigens, and concluded that further investigations with other batches of the lecithin were warranted. Reyn and Bentzon (1956) showed that

* Received for publication, May 23, 1957. the synthetic crystalline material could replace natural lecithin in cardiolipin antigens, but found that the antigens prepared with the synthetic lecithin were significantly less sensitive than those prepared with an equimolar amount of natural lecithin. Faure and Vaissière (1956) reported them to be only slightly less sensitive than natural lecithin antigens and much improved in stability over antigens containing the original non-crystalline synthetic lecithin.

We have studied these compounds $\dagger$ for several years and have published a preliminary report (Tonks and Allen, 1953) on the use of $L-\alpha-$ (distearoyl)-, L- $\alpha$-(dipalmitoyl)-, and D-, L-, and DL- $\alpha$-(dimyristoyl)-lecithins in antigens for the sero-diagnosis of syphilis. Our first studies were carried out with $\mathrm{L}-\alpha$-(distearoyl)-lecithin. It was possible to prepare reactive antigens with this compound, but because of its limited solubility and the formation of precipitates when mixed with cardiolipin in alcohol solution it was soon discarded in favour of the more soluble dipalmitoyl and dimyristoyl lecithins. We have tested many different antigens containing these compounds and have found that dimyristoyl lecithin is much more satisfactory than dipalmitoyl lecithin as an antigen component. The effects of various modifications of the VDRL test technique, using synthetic lecithin antigens, have been studied; and we have determined optimum compositions for VDRL and Kolmer antigens containing dimyristoyl lecithins.

t All synthetic lecithin materials in these studies were supplied by Dr. Erich Baer. We gratefully acknowledee his help. 
Extensive studies of stability, sensitivity, and specificity have been made, and have led to the conclusion that dimyristoyl lecithins can be used satisfactorily in cardiolipin antigens.

\section{Preparation of Antigens}

Solutions of the lecithins in absolute ethanol were prepared, usually in concentrations of $15 \mathrm{mg} . / \mathrm{ml}$. ( 1.5 per cent.), by dissolving weighed amounts in accurately measured volumes of the alcohol. Antigens were prepared by mixing various volumes of these solutions with alcohol solutions of cardiolipin (Sylvana) and cholesterol (Pfanstiehl) and then adding sufficient alcohol to bring them to the correct final volume (usually $2.5 \mathrm{ml}$.). For example, the experimental batches of our H89L antigen for the VDRL test were prepared by mixing $0.114 \mathrm{ml}$. of 0.56 per cent. cardiolipin solution; $0.5 \mathrm{ml}$. of 1.5 per cent. synthetic $L-\alpha$-(dimyristoyl)-lecithin solution, $1.5 \mathrm{ml}$. of 1.5 per cent. cholesterol solution, and $0.386 \mathrm{ml}$. alcohol. The antigens were made up in small bottles having foil-lined screw caps, and were kept at room temperature in a dark cupboard.

\section{Studies With Distearoyl Lecithin}

Two lots of the distearoyl lecithin were studied. Stock alcohol solutions containing about $6 \mathrm{mg} . / \mathrm{ml}$. ( 0.6 per cent.) were prepared; in each case a small amount of material would not dissolve. When this was removed by filtration, a clear solution resulted. Various antigens containing 0.01 to 0.03 per cent. cardiolipin, 0.02 to 0.2 per cent. lecithin, and 0.3 to 0.9 per cent. cholesterol were prepared. Precipitation occurred in all of these except one containing 0.01 per cent. cardiolipin, 0.02 per cent. lecithin, and 0.9 per cent. cholesterol. The precipitates formed only when cardiolipin was present with the lecithin; their size increased as the lecithin content became greater. After removal of the solid material, the solutions were tested as antigens against strongly positive sera. Very little reactivity was noted in the VDRL test, probably because of the low lecithin content. After the removal of the small amount of precipitate which formed, antigen H11 (composition 0.0175-0.02-0.3)* showed reactivity in the Kolmer test. However, because of the solubility difficulties, no further work was carried out with the distearoyl lecithin.

\footnotetext{
* In many parts of this paper, the composition of antigens will be given in this manner, expressed as concentrations in g. $/ 100 \mathrm{ml}$ (referred to as per cent.). The sequence of the components wil always be as follows: cardiolipin lecithin, cholesterol for ents wil H11 cemposition $0.0175-0.02-0.3)$, cholesterol. For example, cardiolipin, 0.02 per cent. lecithin, and 0.3 per cent. cholesterol.
}

II. Studies with L- $\alpha$-(Dipalmitoyl $\dagger$ )-Lecithin AND L-, D-, AND DL- $\alpha-$ (DIMYRISTOYL $\dagger)-$ LeCITHINS IN ANTIGeNS FOR THE VDRL TEST

\section{Selection of Optimum Antigen Compositions and Test Conditions}

\section{Method}

Preliminary studies showed that antigens containing either $\mathrm{L}-\alpha$-(dipalmitoyl)-lecithin (L- $\alpha-\mathrm{DPL})$, or $\mathrm{L}-\alpha-$ (dimyristoyl)-lecithin ( $\mathrm{L}-\alpha-\mathrm{DML}$ ), in place of Pangborn lecithin, were reactive. Many different antigens were then prepared and compared serologically with standard VDRL antigen. Even the most sensitive of these did not give the desired reactivity; therefore different methods of preparing and treating the antigen suspension, and of performing the test itself, were investigated in attempts to increase reactivity. New series of antigens were then prepared and tested in order to find two of standard sensitivity. These studies were carried out with lecithins synthesized and purified by Baer's original method (Baer and Kates, 1950). When the more stable crystalline materials became available, much of the work was repeated with them.

\section{Results}

(A) Studies with Antigen Suspensions for the VDRL Test.-The initial studies were carried out with antigen H56 (composition 0.03-0.18-0.9) containing $\mathrm{L}-\alpha-\mathrm{DPL}$, and antigen $\mathrm{H} 78$ (composition $0.02-0 \cdot 18-0.9)$ containing $\mathrm{L}-\alpha-\mathrm{DML}$. The work was repeated with antigen $\mathrm{H} 89 \mathrm{~L}$ containing crystalline $\mathrm{L}-\alpha$-DML (composition $0.03-0 \cdot 30-0.9$ ) and with antigens H89D and H89DL of this same composition containing the D- and DL-forms of crystalline DML, respectively.

(1) Effect of Standing at Room Temperature.With DML antigen suspensions, an increase in the size of floccules formed with positive sera was observed after the suspensions had been allowed to stand in closed bottles at room temperature. In one experiment a number of suspensions were prepared from an antigen at different times over a period of $24 \mathrm{hrs}$, and then all were tested in parallel using a group of positive and negative sera. In another experiment, a single suspension was prepared and tested at intervals over a $24-\mathrm{hr}$ period. It was found that the reactivity increased gradually for $3 \frac{1}{2}$ to $4 \mathrm{hrs}$, then remained nearly constant for the remainder of the test period. There was a slight increase in particle size in the suspensions themselves, but not sufficient to interfere with negative

† DML and DPL will be used as abbreviations for dimyristoyl lecithin and dipalmitoyl lecithin respectively. 
readings. With antigens containing crystalline DML material, the changes did not appear to be as great.

Suspensions prepared from DPL antigens showed little change in reactivity upon standing.

(2) Effect of Heating for Short Periods at $56^{\circ}$ C.Suspensions of DML antigen were heated in closed bottles at $56^{\circ} \mathrm{C}$. for periods ranging from 2 to $10 \mathrm{~min}$., were allowed to cool, and then were tested with individual sera. The heated suspensions showed an increased reactivity when compared with freshlyprepared unheated ones. Somewhat larger clumps formed with positive sera. There was a slight increase in particle size in the suspensions themselves, but this was not large enough to interfere with negative readings. After heating, the suspensions maintained a nearly constant level of reactivity for at least $24 \mathrm{hrs}$. Suspensions prepared from antigens containing crystalline $\mathrm{DML}$ also increased in reactivity when heated; however, the changes were again not as large as with antigens containing the original synthetic lecithin preparations. Suspensions from DPL antigens did not change significantly in their reactivity when heated.

Since the effect of heating seemed to be similar to that of standing for $4 \mathrm{hrs}$ at room temperature, a direct comparison was made. Parallel tests, using a large number of individual sera, were conducted with DML antigen suspensions which had been heated for $5 \mathrm{~min}$. at $56^{\circ} \mathrm{C}$. and then cooled, and with similar unheated ones which had stood for $4 \mathrm{hrs}$. Almost identical results were obtained. Since the heating quickly produced stable suspensions of maximum sensitivity, it was decided to include it as part of our procedure for preparing them. It is doubtful whether this additional step is necessary for crystalline DML antigen suspensions which are intended for routine use, because the changes in reactivity involved are rather small; however, for comparative studies we consider it to be advisable. In this regard, it should be mentioned that Reyn, Bentzon, and Hartmann (1956) found that heating suspensions at $56^{\circ} \mathrm{C}$. for periods up to $4 \mathrm{hrs}$ did not improve flocculation.

It was interesting to find that the heating of suspensions of Pangborn lecithin antigens in a similar manner increased reactivity markedly, much more than with the synthetic lecithin antigens.

(3) Other Variations in the Method of Preparation.-In the regular method of preparing the suspensions, $0.4 \mathrm{ml}$. buffered saline solution is added to the mixing bottle followed by $0.5 \mathrm{ml}$. antigen with continuous rotation of the bottle.
Then $4 \cdot 1 \mathrm{ml}$. buffered saline solution is added with further mixing to complete the preparation. With DML antigens we varied the initial amounts of saline used over a wide range, but with no apparent advantage. Varying the volume of antigen resulted only in decreased reactivity, and when less than the recommended amount was used, there was also a noticeable decrease in the number of particles.

The use of cold saline and cold antigen in the preparation of the suspensions and the storage of the suspensions in the cold did not result in any improvement in the floccules formed with positive sera.

(B) Variations in VDRL Test Technique.-In further efforts to increase the size of floccules formed by the synthetic lecithin antigens, variations in the technique itself were studied, using DML antigen H89L. Different amounts of suspension, ranging from $1 / 25 \mathrm{ml}$. to $1 / 130 \mathrm{ml}$., were added to the usual $1 / 20 \mathrm{ml}$. serum. With positive sera, the largest floccules were obtained with $1 / 50 \mathrm{ml}$. suspension; however, rough negatives were formed with this amount and with larger volumes. Also, with the latter, too many floccules formed for satisfactory readings. Amounts less than $1 / 60 \mathrm{ml}$., the usual volume, gave too few particles. It was concluded therefore that $1 / 60 \mathrm{ml}$. was the most satisfactory quantity to use.

The mixing time was increased from 4 to $8 \mathrm{~min}$. This resulted in a slight increase in floccule size, but it was not large enough to warrant changing the standard technique.

(C) Final Technique for the VDRL Test.-Our tests have indicated that the regular technique for the VDRL test (U.S. Public Health Service, 1949) is probably the most satisfactory for antigens containing the synthetic saturated lecithins. It was decided therefore to adhere to this technique exactly, with the single exception of heating the antigen suspensions for $5 \mathrm{~min}$. at $56^{\circ} \mathrm{C}$. within a short time of their preparation. We carry out this step by partially immersing in water at $56^{\circ} \mathrm{C}$. the small glassstoppered bottles containing the prepared suspensions. We then allow them to cool to room temperature before use. As mentioned above, this change in technique may not be necessary or advisable for routine examinations; however, we feel that somewhat more reproducible results are obtained by its use.

(D) Optimum Antigen Compositions (VDRL Test.)A large number of antigens of different compositions containing DPL or DML were prepared and 
TABLE I

VDRL TEST.

DIPALMITOYL LECITHIN ANTIGENS COMPARED WITH STANDARD ANTIGEN

\begin{tabular}{|c|c|c|c|c|c|}
\hline \multirow{2}{*}{$\begin{array}{l}\text { Cardiolipin } \\
(\mathrm{g} . / 100 \mathrm{ml} .)\end{array}$} & \multirow{2}{*}{$\begin{array}{l}\text { Lecithin } \\
(\mathrm{g} . / 100 \mathrm{ml} .)\end{array}$} & \multirow{2}{*}{$\begin{array}{c}\text { Ratio of Cardiolipin } \\
\text { to Lecithin }\end{array}$} & \multicolumn{2}{|c|}{ Comparison with Standard Antigen } & \multirow[b]{2}{*}{ Antigen No. } \\
\hline & & & $\begin{array}{l}\text { Reactivity with } \\
\text { Positive Sera }\end{array}$ & $\begin{array}{l}\text { Particle Size with } \\
\text { Negative Sera }\end{array}$ & \\
\hline 0.01 & $\begin{array}{l}0 \cdot 06 \\
0 \cdot 09 \\
0 \cdot 11 \\
0 \cdot 13 \\
0 \cdot 15 \\
0 \cdot 18 \\
0 \cdot 21\end{array}$ & $\begin{array}{l:l}1 & : 6 \\
1: 9 \\
1: 11 \\
1: 13 \\
1: 15 \\
1: 18 \\
1: 21\end{array}$ & $\begin{array}{l}\text { Weaker } \\
\text { Weaker } \\
\text { Slightly weaker } \\
\text { Similar } \\
\text { Slightly stronger } \\
\text { Stronger } \\
\text { Stronger }\end{array}$ & $\begin{array}{l}\text { Slightly larger } \\
\text { Slightly larger } \\
\text { Slightly larger } \\
\text { Larger } \\
\text { 'Larger } \\
\text { Larger } \\
\text { Larger }\end{array}$ & $\begin{array}{l}\text { H29 } \\
\text { H114 } \\
\text { H115 } \\
\text { H116 } \\
\text { H117 } \\
\text { H45 } \\
\text { H118 }\end{array}$ \\
\hline 0.02 & $\begin{array}{l}0 \cdot 12 \\
0 \cdot 18 \\
0 \cdot 20 \\
0 \cdot 22 \\
0 \cdot 26 \\
0 \cdot 30 \\
0 \cdot 36 \\
0 \cdot 50\end{array}$ & $\begin{array}{l:l}1 & : 6 \\
1 & : 9 \\
1 & : 10 \\
1 & 11 \\
1 & : 13 \\
1 & : 15 \\
1 & : 18 \\
1 & : 25\end{array}$ & $\begin{array}{l}\text { Weaker } \\
\text { Slightly weaker } \\
\text { Similar } \\
\text { Similar } \\
\text { (Tendency to form } \\
\text { crystals and loose } \\
\text { clumps) }\end{array}$ & $\begin{array}{l}\text { Slightly larger } \\
\text { Slightly larger } \\
\text { Slightly larger } \\
\text { Slightly larger } \\
\text { Slightly larger } \\
\text { Slightly larger } \\
\text { Larger } \\
\text { Much larger }\end{array}$ & $\begin{array}{l}\text { H143 } \\
\text { H50 } \\
\text { H145 } \\
\text { H51 } \\
\text { H52 } \\
\text { H53 } \\
\text { H146 } \\
\text { H148 }\end{array}$ \\
\hline 0.04 & $\begin{array}{l}0 \cdot 16 \\
0 \cdot 24 \\
0 \cdot 28 \\
0 \cdot 32 \\
0 \cdot 36 \\
0 \cdot 44\end{array}$ & $\begin{array}{l}1: 4 \\
1: 6 \\
1: 7 \\
1: 8 \\
1: 9 \\
1: 11\end{array}$ & $\begin{array}{l}\text { Weaker } \\
\text { Weaker } \\
\text { Weaker } \\
\text { (Tendency to form } \\
\text { crystals and loose } \\
\text { clumps) }\end{array}$ & $\begin{array}{l}\text { Same } \\
\text { Slightly larger } \\
\text { Slightly larger } \\
\text { Slightly larger } \\
\text { Larger, with long } \\
\text { crystals }\end{array}$ & $\begin{array}{l}\text { H186 } \\
\text { H187 } \\
\text { H188 } \\
\text { H161 } \\
\text { H189 } \\
\text { H190 }\end{array}$ \\
\hline
\end{tabular}

compared serologically with our standard antigen in order to determine which compositions would give standard reactivity. Tests were performed upon individual sera, both positive and negative, and upon dilutions of positive serum pools which gave reactions of varying degrees with the standard antigen.

(I) With L- $\alpha$-(dipalmitoyl)-Lecithin.-Antigens were prepared containing either $0.01,0.02,0.03$, or 0.04 per cent. cardiolipin, varying amounts of DPL, and 0.9 per cent. cholesterol. The results of comparisons with standard VDRL antigen are given in Table I.

At the higher lecithin concentrations, DPL antigens with $0.02,0.03$, and 0.04 per cent. cardiolipin gave atypical floccules of a loose crystalline nature. This tendency became greater as the percentages of cardiolipin and of lecithin were increased. The most satisfactory antigens were H116 (composition $0.01-0 \cdot 13-0.9$ ) and H145 $(0.02-0 \cdot 20-0.9)$; however, the floccules they gave with positive sera were smaller than those obtained with regular VDRL antigen, and with negative sera there was a tendency towards roughness (i.e. larger particle size). Antigens giving larger clumps with positive sera were not satisfactory because the clumps were usually loosely formed and seemed to contain long crystalline particles. With these antigens, also, there was often a considerable increase in particle size with negative sera.

(2) With $L-, \quad D-$, and $D L-\alpha-($ dimyristoyl)Lecithins. - Antigens were prepared containing either $0.01,0.02$, or 0.03 per cent. cardiolipin, varying amounts of $\mathrm{L}-\alpha$-(dimyristoyl)-lecithin, and 0.9 per cent. cholesterol.* The results of comparisons with regular VDRL antigen are given in Table II (opposite).

The DML antigens proved to be more satisfactory than those with DPL. There was no tendency to form atypical floccules. With all three of the cardiolipin concentrations, there was a gradual increase in sensitivity with increasing lecithin concentration until a maximum was reached; further increases in the lecithin then caused the sensitivity to decrease. With negative sera, fine particles were obtained with the lower lecithin concentrations, but their size increased at the higher concentrations as indicated in Table II.

* Previous results indicated that neither increasing nor decreasing the cholesterol concentration improved the quality of the antigens. 
TABLE II

VDRL TEST.

DIMYRISTOYL LECITHIN ANTIGENS COMPARED WITH STANDARD ANTIGEN

\begin{tabular}{|c|c|c|c|c|c|}
\hline \multirow{2}{*}{$\begin{array}{l}\text { Cardiolipin } \\
\text { (g./100 ml.) }\end{array}$} & \multirow{2}{*}{$\begin{array}{c}\text { Lecithin } \\
\text { (g. } / 100 \mathrm{ml} .)\end{array}$} & \multirow{2}{*}{$\begin{array}{l}\text { Ratio of Cardiolipin } \\
\text { to Lecithin }\end{array}$} & \multicolumn{2}{|c|}{ Comparison with Standard Antigen } & \multirow{2}{*}{ Antigen No. } \\
\hline & & & $\begin{array}{l}\text { Reactivity with } \\
\text { Positive Sera }\end{array}$ & $\begin{array}{l}\text { Particle Size with } \\
\text { Negative Sera }\end{array}$ & \\
\hline 0.01 & $\begin{array}{l}0 \cdot 09 \\
0 \cdot 10 \\
0 \cdot 11 \\
0 \cdot 12 \\
0 \cdot 13 \\
0 \cdot 15 \\
0 \cdot 17 \\
0 \cdot 20 \\
0 \cdot 22 \\
0 \cdot 25\end{array}$ & $\begin{array}{l:l}1 & : 9 \\
1 & : 10 \\
1 & 11 \\
1 & : 12 \\
1 & : 13 \\
1 & : 15 \\
1 & : 17 \\
1 & : 20 \\
1 & : 22 \\
1 & : 25\end{array}$ & $\begin{array}{l}\text { Weaker } \\
\text { Slightly weaker } \\
\text { Similar } \\
\text { Slightly stronger } \\
\text { Stronger } \\
\text { Stronger } \\
\text { Stronger } \\
\text { Stronger } \\
\text { Stronger } \\
\text { Slightly stronger }\end{array}$ & $\begin{array}{l}\text { Similar } \\
\text { Similar } \\
\text { Similar } \\
\text { Similar } \\
\text { Slightly larger } \\
\text { Slightly larger } \\
\text { Larger } \\
\text { Larger } \\
\text { Larger } \\
\text { Larger }\end{array}$ & $\begin{array}{l}\text { H104 } \\
\text { H69 } \\
\text { H105 } \\
\text { H106 } \\
\text { H107 } \\
\text { H108 } \\
\text { H162 } \\
\text { H163 } \\
\text { H168 } \\
\text { H110 }\end{array}$ \\
\hline 0.02 & $\begin{array}{l}0 \cdot 10 \\
0 \cdot 12 \\
0 \cdot 14 \\
0 \cdot 16 \\
0 \cdot 18 \\
0 \cdot 20 \\
0 \cdot 22 \\
0 \cdot 24 \\
0 \cdot 26 \\
0 \cdot 30 \\
0 \cdot 38\end{array}$ & $\begin{array}{l:l}1 & : 5 \\
1 & : 6 \\
1 & 7 \\
1 & : 8 \\
1 & : 9 \\
1 & : 10 \\
1 & : 11 \\
1 & : 12 \\
1 & : 13 \\
1 & : 15 \\
1 & : 19\end{array}$ & $\begin{array}{l}\text { Weaker } \\
\text { Similar } \\
\text { Slightly stronger } \\
\text { Stronger } \\
\text { Stronger } \\
\text { Stronger } \\
\text { Stronger } \\
\text { Stronger } \\
\text { Slightly stronger } \\
\text { Similar } \\
\text { Weaker }\end{array}$ & $\begin{array}{l}\text { Similar } \\
\text { Similar } \\
\text { Similar } \\
\text { Similar } \\
\text { Similar } \\
\text { Similar } \\
\text { Slightly larger } \\
\text { Larger } \\
\text { Larger } \\
\text { Larger } \\
\text { Much larger }\end{array}$ & $\begin{array}{l}\text { H164 } \\
\text { H170 } \\
\text { H165 } \\
\text { H77 } \\
\text { H78 } \\
\text { H111 } \\
\text { H79 } \\
\text { H156 } \\
\text { H80 } \\
\text { H81 } \\
\text { H95 }\end{array}$ \\
\hline 0.03 & $\begin{array}{l}0 \cdot 12 \\
0 \cdot 15 \\
0 \cdot 18 \\
0 \cdot 21 \\
0 \cdot 24 \\
0 \cdot 27 \\
0 \cdot 30 \\
0 \cdot 33 \\
0 \cdot 39\end{array}$ & $\begin{array}{l:l}1 & : 4 \\
1 & : 5 \\
1 & : 6 \\
1 & : 7 \\
1 & : 8 \\
1 & : 9 \\
1 & : 10 \\
1 & : 11 \\
1 & : 13\end{array}$ & $\begin{array}{l}\text { Weaker } \\
\text { Slightly weaker } \\
\text { Similar } \\
\text { Slightly stronger } \\
\text { Stronger } \\
\text { Slightly stronger } \\
\text { Similar } \\
\text { Slightly weaker } \\
\text { Weaker }\end{array}$ & $\begin{array}{l}\text { Similar } \\
\text { Similar } \\
\text { Similar } \\
\text { Similar } \\
\text { Similar } \\
\text { Similar } \\
\text { Similar } \\
\text { Similar } \\
\text { Slightly larger }\end{array}$ & $\begin{array}{l}\text { H166 } \\
\text { H173 } \\
\text { H167 } \\
\text { H157 } \\
\text { H158 } \\
\text { H159 } \\
\text { H89 } \\
\text { H160 } \\
\text { H112 }\end{array}$ \\
\hline
\end{tabular}

The following antigens were found to behave similarly to the standard antigen with positive sera:

$$
\begin{aligned}
& \text { H105 (composition } 0.01-0.11-0.9) \text {, } \\
& \text { H170 }(0.02-0.12-0.9) \text {, } \\
& \text { H81 }(0.02-0.3-0.9) \text {, } \\
& \text { H167 }(0.03-0.18-0.9) \text {, } \\
& \text { H89 }(0.03-0.3-0.9) \text {. }
\end{aligned}
$$

Antigen $\mathrm{H} 81$, however, gave too large particles with negative sera to be considered as satisfactory. A cardiolipin level of 0.03 per cent. appeared to give the smallest particles with negative sera and also the most reproducible results. Antigen $\mathbf{H 8 9}$ was finally chosen as the one to be studied further.

Many of these studies were repeated with antigens containing the D- and DL- forms of dimyristoyl lecithin, and, as expected, similar results were obtained. Antigens containing the three forms in the same concentrations (composition 0.03-0.30-0.9), when tested in parallel, gave nearly identical readings which were also close to those obtained with the standard VDRL antigen (see Part V).

A DML antigen of composition 0.03-0.255-0.9 (H178) was prepared and compared with our regular VDRL antigen $(0 \cdot 03-0 \cdot 22-0 \cdot 9$, with Pangborn's lecithin), and with another containing a larger amount of Pangborn's lecithin (0.03$0 \cdot 27-0 \cdot 9$ ). The last of these had the same composition as the standard VDRL antigen used by Reyn, Bentzon, and Hartmann (1956), and by Faure and Vaissière (1956). Tests with positive and negative sera showed that $\mathrm{H} 178$ was more reactive than our standard antigen but slightly less reactive than the one containing 0.27 per cent. natural lecithin. These findings are in agreement with those of the other investigators.

\section{Discussion}

The above results indicated that it was possible to prepare antigens for the VDRL test of satisfactory reactivity when Pangborn's lecithin was replaced by any one of the three synthetic saturated dimyristoyl lecithins. There remained, however, the questions of the stability of these substances and of the stability and specificity of antigens prepared from them. These properties were now studied in detail; the results of these studies and of further sensitivity evaluations with $\mathrm{H} 89$ antigens are given in Sections IV and V of this paper.

Of the three enantiomeric forms of $\alpha$-(dimyristoyl)lecithin, the DL- form is considered to be the easiest to prepare (Baer, Martin, Allen, and Tonks, 
1951); therefore it would appear to be the best choice for antigens for routine use. It should be mentioned that the floccules formed by antigens containing these lecithins are not identical in appearance and size with those produced by antigens containing Pangborn's lecithin. They tend to be somewhat smaller, especially with strongly reactive serum, and large black clumps are seldom seen. Nevertheless, different degrees of reaction are readily distinguishable.

The dipalmitoyl lecithin antigens were generally unsatisfactory because of low reactivity or atypical floccule formation. Although certain of them showed promise, no further work was conducted with this lecithin because of the availability of the more suitable dimyristoyl compounds.

In previous papers (Tonks and Allen, 1953; Tonks, Allen, and Fowler, 1955) we stated that VDRL antigen of composition 0.03-0.3-0.9 containing Baer's DPL gave satisfactory results. However, our more recent studies, which are reported in this paper, have indicated that DPL is probably not suitable for use as the lecithin component in VDRL antigens at least. This conclusion is supported by the results we have obtained (Tonks, Allen, and Fowler, 1955) with L- $\alpha$-DPL prepared by Hanahan and Jayko (1952) by hydrogenation of pure L- $\alpha$-(dipalmitoleoyl)-lecithin. When similar antigens containing Baer's or Hanahan's DPL were tested in parallel, their behaviours were almost identical.

\section{Studies With D-, L-, ANd DL- $\alpha$-(Dimyris- TOYL)-LECITHINS, AND L- $\alpha$-(DiPALMITOYL)- LeCithin IN ANTIGENS FOR the Kolmer Test}

\section{Selection of Optimum Antigen Compositions}

Preliminary experiments indicated that antigens containing the earlier preparations of DPL and DML were reactive in the Kolmer test. Antigens of the same composition as our standard Kolmer cardiolipin antigen $(0.0175-0 \cdot 2-0.3)$ had about the same level of reactivity as the standard antigen (Tonks and Allen, 1953), whereas those with compositions $0.03-0.05-0.3$ and $0.0175-0.0875-$ 0.3 were too reactive. Since it appeared that there would be no difficulty in obtaining an antigen of the desired sensitivity, it was not necessary to study and modify the test technique (U.S. Public Health Service, 1949). Antigen dilutions of $1: 300$ were found to be generally satisfactory. Titrations with various dilutions of the antigens showed no haemolytic effects when dilutions were greater than $1: 4$. No positive reactions were obtained with antigen of composition $0 \cdot 0175-0 \cdot 2-0 \cdot 3$ when it was tested with 44 normal sera.

When the crystalline lecithin preparations became available in 1952, a series of antigens containing D- $\alpha-D M L$ in varying amounts, 0.0175 per cent. cardiolipin, and 0.3 per cent. cholesterol were prepared and tested serologically in order to determine the optimum concentration of the lecithin.

\section{Results}

The results of these studies are summarized in Table III.

TABLE III

KOLMER TEST

D- $\alpha$-(DIMYRISTOYL)-LECITHIN ANTIGENS* COMPARED WITH STANDARD ANTIGEN

\begin{tabular}{c|c|l|c}
\hline $\begin{array}{c}\text { Lecithin } \\
\text { (g./100 ml.) }\end{array}$ & $\begin{array}{c}\text { Ratio of Cardiolipin } \\
\text { to Lecithin }\end{array}$ & $\begin{array}{l}\text { Comparison with } \\
\text { Standard Antigen }\end{array}$ & $\begin{array}{c}\text { Antigen } \\
\text { No. }\end{array}$ \\
\hline 0.0525 & $1: 3$ & Stronger & K 50 \\
$0 \cdot 0700$ & $1: 4$ & Stronger & K 51 \\
$0 \cdot 0875$ & $1: 5$ & Stronger & K 52 \\
$0 \cdot 1050$ & $1: 6$ & Slightly stronger & K 53 \\
$0 \cdot 1225$ & $1 \vdots 7$ & Similar & K 54 \\
$0 \cdot 1575$ & $1: 9$ & Slightly weaker & K 55 \\
$0 \cdot 1750$ & $1: 10$ & Weaker & K 56 \\
$0 \cdot 200$ & $1: 11 \cdot 4$ & Weaker & K 57 \\
\hline
\end{tabular}

* All these antigens contained 0.0175 per cent. cardiolipin and $0 \cdot 3$ per cent. cholesterol.

Antigen K54 (composition $0 \cdot 0175-0 \cdot 1225-0 \cdot 3$ ) was found to be the nearest in sensitivity to the standard antigen. The three enantiomeric forms of DML were then compared serologically in antigens of this optimum composition (Section V). The $\mathbf{L}$-form was tested for stability over a 3-year period (Section IV).

Although most of the studies with the Kolmer test were carried out with DML, some comparisons were also made with antigen of composition $0 \cdot 0175-0 \cdot 1225-0.3$ containing Baer's DPL and Hanahan's DPL (Hanahan and Jayko, 1952). They were somewhat less reactive than the standard antigen, but were very close to each other in sensitivity.

\section{Stability Studies With L- $\alpha$-(Dimyristoyl)- LECITHIN \\ Method}

An extensive study was conducted to determine the stability of $\mathrm{L}-\alpha$-(dimyristoyl)-lecithin (DML) in the solid form and in alcohol solution and to determine as well the stability of antigens containing this lecithin in place of Pangborn lecithin. In each phase of the main experiment, which extended over a year, portions of the antigen and of the alcohol solution were stored at room temperature and at $6^{\circ} \mathrm{C}$. in a refrigerator. Portions of the 
solid material were also stored under these conditions. Antigens were prepared for both the VDRL microflocculation test and the Kolmer complement-fixation test.

Crystalline DML, which had been prepared by Dr. Baer and his associates in July, 1952, was used throughout the study. For the VDRL test, antigens of composition $0.0267-0.30-0.9$ were used; for the Kolmer test, the composition was $0 \cdot 0105-0 \cdot 1225-0 \cdot 9$.* Those prepared at the beginning of the experiment in February, 1953 , were compared serologically with standard antigens at that time and at 3-monthly intervals thereafter for a period of a year. Also, every 3 months, antigens were prepared from the stock alcohol solutions prepared in February, 1953, and tested. After 6 months and 12 months, alcohol solutions were prepared from the solid lecithin and incorporated into antigens for testing.

For the serological comparisons, the following test materials were used:

(a) Partially positive individual sera.

(b) Dehydrated pooled syphilitic serum which had been diluted with four parts of saline before drying. After reconstitution of the contents of an ampoule with water, a series of dilutions with saline was prepared and tested. Two dried pools were used throughout.

At each test period, serological comparisons were conducted on several consecutive days. The total number of weakly-positive specimens examined usually exceeded twenty.

\section{Results}

These studies have indicated a satisfactory degree of stability. Dimyristoyl lecithin was found to be stable for at least a year in the solid form and in alcohol solution, both at room and refrigerator temperatures. Antigens containing it in place of Pangborn lecithin did not vary appreciably in sensitivity over the 12 -month period. Indeed, one of the samples of antigen prepared in February of 1953 for the Kolmer test showed no evidence of a change in reactivity after storage at room temperature for 3 years.

\section{Discussion}

Before the initiation of this project, Faure and Maréchal (1952) observed and reported a marked instability of antigens containing dimyristoyl lecithin prepared for the Kline test and, to a lesser extent, of antigens prepared for the Debains and the Kolmer complement-fixation tests. More recently, Faure and Vaissière (1956) have reported a satisfactory stability when antigens prepared for the Kline and

* Because of a misunderstanding, these compositions were used throughout instead of the ones considered to give standard reactivity: $0.03-0.3-0.9$ for the VDRL test, and $0.0175-0.1225-0.3$ for the Kolmer test.
Kolmer tests and containing crystalline dimyristoyl lecithin were stored for 6 months. It seems that Baer's crystalline preparations are more stable than his earlier ones; however, we did not detect any marked instability of antigens containing the latter, as was observed by Faure and Maréchal.

Reyn and Bentzon (1956) studied the stability of DML antigens for the Mørch complement-fixation test and the VDRL microflocculation test and found no changes in the relative reactivities of the tests and reference antigens. However, they demonstrated that antigens containing crystalline synthetic lecithin showed a greater loss in sensitivity when kept at $56^{\circ} \mathrm{C}$. for 4 months than did antigens containing purified, natural egg lecithin (Reyn, Bentzon, and Hartmann, 1956).

\section{Clinical Evaluation of Kolmer and VDRL Antigens Containing L-, D-, AND DL- $\alpha$-(DiMYRISTOYL)-LeCITHINS \\ Method}

DML antigens of standard sensitivity (as selected in Part 3) were prepared in quantity for routine diagnostic use. Various individual sera, obtained from patients at a local venereal diseases clinic, were tested with these antigens and also with our standard diagnostic antigens, and the results were correlated with the clinical histories of the patients.

Crystalline samples of D-, L- and DL- $\alpha$-(dimyristoyl) -lecithins, obtained from Dr. Baer, were used in the antigens. The antigens were composed as follows:

(a) for the VDRL test, $0 \cdot 03-0 \cdot 3-0 \cdot 9$;

(b) for the Kolmer test, $0 \cdot 0175-0 \cdot 1225-0 \cdot 3$.

The antigens were stored at room temperature throughout the study which took place over a period of one year. The VDRL and Kolmer tests were carried out as prescribed by the U.S. Public Health Service (1949), except that suspensions of dimyristoyl lecithin antigens for the VDRL test were heated at $56^{\circ} \mathrm{C}$. for $5 \mathrm{~min}$. soon after their preparation, and were then allowed to cool to room temperature before use.

\section{Results}

Results obtained in specimens from treated and untreated cases of syphilis are summarized in the first sections of Tables IV and V (overleaf).

In the VDRL test there was close agreement between standard antigen and antigens containing the three dimyristoyl lecithins. In the Kolmer test, the standard antigen was slightly less sensitive than the saturated lecithin antigens, although the latter agree closely with each other. 
TABLE IV

VDRL TEST.

ANTIGENS (COMPOSITION $0 \cdot 03-0 \cdot 30-0 \cdot 9)$ CONTAINING D-, L-, AND DL- $\alpha$-(DIMYRISTOYL)-LECITHINS COMPARED WITH STANDARD' VDRL ANTIGEN

\begin{tabular}{|c|c|c|c|c|c|c|}
\hline Sera & Antigen containing & Per Cent. Positive & Per Cent. Doubtful & Per Cent. Negative & & \\
\hline \multirow{4}{*}{$\begin{array}{c}446 \text { Specimens } \\
\text { from } \\
\text { Treated } \\
\text { and } \\
\text { Untreated } \\
\text { Cases of } \\
\text { Syphilis }\end{array}$} & D-Lecithin . . & $71 \cdot 3$ & $13 \cdot 5$ & $15 \cdot 2$ & $78 \cdot 1$ & \multirow{4}{*}{ Sensitivity* } \\
\hline & L-Lecithin .. & $70 \cdot 9$ & $13 \cdot 9$ & $15 \cdot 2$ & $77 \cdot 9$ & \\
\hline & DL-Lecithin & $68 \cdot 8$ & $16 \cdot 2$ & $15 \cdot 0$ & $76 \cdot 9$ & \\
\hline & Standard Antigen & $72 \cdot 0$ & $9 \cdot 4$ & $18 \cdot 6$ & $76 \cdot 7$ & \\
\hline \multirow{4}{*}{$\begin{array}{c}231 \text { Specimens } \\
\text { from Individuals } \\
\text { with no } \\
\text { Evidence of } \\
\text { Syphilis } \\
\text { but with } \\
\text { Gonorrhoea }\end{array}$} & D-Lecithin .. & 0 & $1 \cdot 3$ & $98 \cdot 7$ & $99 \cdot 4$ & \multirow{4}{*}{ Specificityt } \\
\hline & L-Lecithin . . & 0 & $1 \cdot 3$ & $98 \cdot 7$ & $99 \cdot 4$ & \\
\hline & DL-Lecithin & 0 & $0 \cdot 8$ & $99 \cdot 2$. & $99 \cdot 6$ & \\
\hline & Standard Antigen . & 0 & $1 \cdot 3$ & $98 \cdot 7$ & $99 \cdot 4$ & \\
\hline \multirow{3}{*}{$\begin{array}{l}69 \text { Specimens } \\
\text { from Individuals } \\
\text { with no } \\
\text { Evidence of } \\
\text { Venereal Disease }\end{array}$} & D-Lecithin .. & 0 & $4 \cdot 3$ & $95 \cdot 7$ & 97.97 & \multirow{3}{*}{ Specificityt } \\
\hline & L-Lecithin .. & 0 & $4 \cdot 3$ & $95 \cdot 7$ & $97 \cdot 9$ & \\
\hline & Standard Antigen & $1 \cdot 45$ & $1 \cdot 45$ & $97 \cdot 1$ & $97 \cdot 8$ & \\
\hline
\end{tabular}

* Sensitivity is the sum of the percentage of positive results and one-half the percentage of doubtful results.

+ Specificity is the sum of the percentage of negative results and one-half the percentage of doubtful results.

TABLE V

KOLMER TEST

ANTIGENS (COMPOSITION 0.0175-0. 1225-0.3) CONTAINING D- L- AND DL- $\alpha$-(DIMYRISTOYL)-LECITHINS COMPARED WITH STANDARD KOLMER ANTIGEN*

\begin{tabular}{|c|c|c|c|c|c|c|c|}
\hline Sera & Antigen containing & & Per Cent. Positive & Per Cent. Doubtful & Per Cent. Negative & & \\
\hline \multirow{4}{*}{$\begin{array}{c}472 \text { Specimens } \\
\text { from } \\
\text { Treated } \\
\text { and } \\
\text { Untreated } \\
\text { Cases of } \\
\text { Syphilis }\end{array}$} & D-Lecithin .. & . & $68 \cdot 9$ & $12 \cdot 3$ & $18 \cdot 8$ & $75 \cdot 1$ & \multirow{4}{*}{ Sensitivity } \\
\hline & L-Lecithin ... & 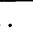 & $69 \cdot 9$ & $11 \cdot 0$ & $19 \cdot 2$ & $\overline{75 \cdot 4}$ & \\
\hline & DL-Lecithin & 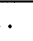 & $69 \cdot 3$ & $12 \cdot 9$ & $17 \cdot 8$ & $\overline{75 \cdot 8}$ & \\
\hline & Standard Antigen & . & $64 \cdot 0$ & $12 \cdot 9$ & $23 \cdot 1$ & $70 \cdot 5$ & \\
\hline \multirow{4}{*}{$\begin{array}{c}249 \text { Specimens } \\
\text { from Individuals } \\
\text { with no } \\
\text { Evidence of } \\
\text { Syphilis } \\
\text { but with } \\
\text { Gonorrhoea }\end{array}$} & D-Lecithin .. & . & 0.4 & $1 \cdot 2$ & $98 \cdot 4$ & $99 \cdot 0$ & \multirow{4}{*}{ Specificity } \\
\hline & L-Lecithin . . & 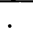 & $0 \cdot 4$ & $2 \cdot 0$ & $97 \cdot 6$ & $98 \cdot 6$ & \\
\hline & DL-Lecithin & . & 0.8 & $0 \cdot 8$ & $98 \cdot 4$ & $98 \cdot 8$ & \\
\hline & Standard Antigen & . & $1 \cdot 2$ & $1 \cdot 6$ & $97 \cdot 2$ & $\overline{98 \cdot 0}$ & \\
\hline \multirow{3}{*}{$\begin{array}{l}84 \text { Specimens } \\
\text { from Individuals } \\
\text { with no } \\
\text { Evidence of } \\
\text { Venereal Disease }\end{array}$} & D-Lecithin .. & . & 0 & 0 & 100 & 100 & \multirow{3}{*}{ Specificity } \\
\hline & L-Lecithin . . &. & 0 & $1 \cdot 2$ & $98 \cdot 8$ & $99 \cdot 4$ & \\
\hline & Standard Antigen & . & 0 & 0 & 100 & 100 & \\
\hline
\end{tabular}

* This antigen is somewhat less reactive than that recommended by Kolmer (Allen and Mason, 1952).

Tables IV and $\mathrm{V}$ also give the results obtained in specimens from individuals with gonorrhoea and from a small group with no evidence of venereal disease. The specificity of the dimyristoyl lecithin antigens compared favourably with that of the respective standard antigens. Considering results obtained with the Kolmer test in patients with gonorrhoea, the specificity with standard Kolmer antigen was the lowest of all. It should be kept in mind that the non-syphilitic groups described in
Tables IV and $\mathbf{V}$ comprised individuals who had presented themselves at a venereal disease clinic for examination, and in whom the existence of syphilis would be more likely than in a normal group.

\section{General Discussion}

The results obtained indicate that any one of the three forms of synthetic dimyristoyl lecithin could be used to replace Pangborn's lecithin in 
VDRL and Kolmer cardiolipin antigens for the diagnosis of syphilis. These synthetic lecithins are stable crystalline powders which are easy to handle and may be incorporated into antigens merely by weighing accurately and dissolving in a definite volume of absolute ethanol. The sensitivities of the antigens can be adjusted to the levels desired in each country or laboratory merely by increasing or decreasing the concentration of the lecithin. In this laboratory we have found a composition of 0.03 per cent. cardiolipin, $0 \cdot 3$ per cent. synthetic dimyristoyl lecithin, and 0.9 per cent. cholesterol to be satisfactory for the VDRL test, whereas for the Kolmer test an antigen composed of 0.0175 per cent. cardiolipin, $0 \cdot 1225$ per cent. synthetic dimyristoyl lecithin, and 0.3 per cent. cholesterol was found to be suitable. These antigens appear to be very similar in specificity to those now used for the Kolmer and VDRL test:

There remains the question of reproducibility of different batches of the synthetic lecithin materials. Serological tests are known to be very sensitive to traces of impurities, some of which may not be detectable by the usual methods of chemical analysis. Up to the present time material has not been available for satisfactory studies of reproducibility. However, we have tested several small batches of each of the dimyristoyl lecithins and have not found any significant differences. $L-\alpha$-(dimyristoyl)lecithin is now being produced commercially and material should therefore be available soon for reproducibility studies. Synthetic lecithins will have little advantage over Pangborn's lecithin if different batches do not give exactly the same results. But if reproducibility is good, the synthetic dimyristoyl lecithins should be very useful for the preparation of cardiolipin antigens.

\section{Summary}

(1) Synthetic $\mathrm{L}-\alpha$-(distearoyl)-, $\mathrm{L}-\alpha-$-(dipalmitoyl), and L-, D-, and DL- $\alpha$-(dimyristoyl)-lecithins have been tested as components in cardiolipin antigens for the VDRL microflocculation and Kolmer complement-fixation tests for the diagnosis of syphilis. The dimyristoyl lecithins were generally satisfactory, but the others were not as suitable. Optimum antigen concentrations have been determined for the dimyristoyl lecithins.

(2) Various modifications of the VDRL microflocculation technique have been tested using antigens containing dipalmitoyl and dimyristoyl lecithins. A slight change in the prescribed procedure has been introduced.

(3) Dimyristoyl lecithin has been found to be stable for at least a year in the solid form and in alcohol solution. Antigens which were prepared for the VDRL and Kolmer tests and which contained this lecithin did not vary appreciably in sensitivity over a period of twelve months.

(4) Dimyristoyl lecithin antigens, used as a matter of routine in testing specimens from individuals with known clinical findings, have compared favourably with our standard antigens.

\section{REFERENCES}

Allen, R. H., and Mason, M. A. (1952). Canad. publ. Hlth J., 43, 128. Baer, E. (1953). J. Amer. chem. Soc., 75, 621.

- and Kates, M. (1949). Science, 109, 31.

- (1950). J. Amer. chem. Soc., 72, 942. Chem., 193, 935 .

and Maurukas, J. (1952), J. Amer chem. Soc, 74, 158

Faure, M., and Maréchal, J. (1952). Ann. Inst. Pasteur, 82, 738.

and Vaissière, C. de la (1956). Bull. Wld Hlth Org., 14, 577.

Kline, B. S. (1950). Amer. J. Syph., 34, 460.

(1954a). Ibid., 38, 578.

(1954b). Amer. J. clin. Path., 24, 859.

(1955). Ibid., 25, 971 .

Hanahan, D. J., and Jayko, M. E. (1952). J. Amer. chem. Soc. 74, 5070.

Reyn, A., and Bentzon, M. W. (1956). Bull. Wld Hlth Org., 14, 567. Bentzon, M. W., and Hartmann, J. (1956). British Journal of Venereal Diseases, 32, 40.

Venereal Diseases, 32, 40.
Rosenberg, A. A. (1949). J. vener. Dis. Inform., 30, 194.

Tonks, D. B., and Allen, R. H. (1953). Science, 118, 55.

,$- \quad-$, and Fowler, E. (1955). British Journal of Venereal Diseases, 31, 180.

U.S. Public Health Service (1949). "Manual of Serologic Tests for Syphilis". J. vener. Dis. Inform., Suppl. 22. 